\title{
Renal Clearance from T1 to T2 Normalized by Dose
}

National Cancer Institute

\section{Source}

National Cancer Institute. Renal Clearance from T1 to T2 Normalized by Dose. NCI

Thesaurus. Code C122331.

The clearance of a substance from the blood by the kidneys over the interval from $\mathrm{T} 1$ to T2 divided by the dose. 